\title{
Experiencing transformation: the case of Jordanian nurse immigrating to the UK
}

\author{
Zaid M Al-Hamdan, Ahmad H Al-Nawafleh, Hala A Bawadi, Veronica James, Milika Matiti and \\ Bonnie M Hagerty
}

Aims and objectives. This study explored how Jordanian nurses experienced the transition from home to host country to illuminate the elements of transformation.

Background. Much research has been conducted on topics such as the current international nursing shortage and the recruitment of nurses from various countries. International nurses have unique needs with regard to adapting to new host cultures and workplaces; furthermore, the literature has revealed little evidence of nurses' professional and personal experiences related to migration.

Design. A qualitative study was conducted, collecting data via individual interviews.

Methods. Twenty-five face-to-face and telephone interviews with Jordanian migrant nurses.

Result. This study showed that living and working in a host country changes the personal, social and professional attributes of migrant nurses. When nurses migrate, they encounter opportunities and significant challenges in their professional and personal lives. Although Jordanian nurses contributed their knowledge and skills to the UK healthcare system, they encountered enormous professional adaptation demands. Work setting discrepancies between source and host country are likely a major element behind the required nursing profession alteration. Nurses' lives are transformed in terms of their personal and social networks in the host country.

Conclusions. Social transformation is an integral and inseparable part of engagement with professional organisation(s) in the host community. Professional integration likely has far-reaching effects and consequences involving not only the individual but also their home and host country families and their professional networks.

Relevance to clinical practice. To provide high-quality nursing care, we must learn about the transformation experience, expand our sense of who we are and gain a degree of control over how we perform our nursing roles when we move away from our home.
What does this paper contribute to the wider global clinical community?

- Migrant nurses' experiences portray differences in the work setting between the present and former environment.

- Professional transformation is the outcome of integration into a new work place and is promoted by differences in policies and regulations of nursing practice between the source and host country.

- Migrant nurses experienced a professional transformation because the education and work policies in the UK adopt evidence-based practice.
Authors: Zaid M Al-Hamdan, PhD, RN, Assistant Professor, Faculty of Nursing, Jordan University of Science and Technology, Irbid, Jordan; Ahmad H Al-Nawafleh, PhD, RN, Assistant Professor, Faculty of Nursing, Mutah University, AlKarak; Hala A Bawadi, PhD, RN, RM, Lecturer, Faculty of Nursing, The University of Jordan, Amman, Jordan; Veronica James, PhD, RN, Professor of nursing studies, Executive Dean of School of Health and Life Sciences, Glasgow Caledonian University, Glasgow;
Milika Matiti, PhD, RN, Lecturer, School of Nursing, University of Nottingham, Boston, UK; Bonnie M. Hagerty, PhD, RN, Associate Professor, School of Nursing, University of Michigan, Ann Arbor, MI, USA

Correspondence: Zaid M Al-Hamdan, Assistant Professor, Faculty of Nursing, Jordan University of Science and Technology, P.O.Box 3030, Irbid 22110, Jordan. Telephone: +962795853482.

E-mail: zaid_hamdan@hotmail.com 
Key words: culture, integration, international nurse experience, nurse migration, personal and professional transformation

Accepted for publication: 14 February 2015

\section{Introduction}

Nurses are increasingly important in international workforce management because they represent the largest and fastest-growing group of healthcare workers. Healthcare workforce migration is assuming global importance as 'workers seek opportunities and job security in dynamic health labour markets that are part of the global political economy' (WHO 2006, p. xvii). As healthcare workforce migration increases, national health workforce figures become integral to the global economy and an understanding of international migration patterns becomes part of national and local workforce planning.

As with other economic migrants, numerous studies have found that nurses are driven by the desire to experience a life different from that within their own home country (Walters 2008, McGillis Hall et al. 2009, Irene et al. 2010, Okougha \& Tilki 2010). Like other migrants, migration transforms nurses' socioeconomic status (Fussell and Massey 2004). However, although extensive theoretical and empirical studies exist on migration (Arango 2000, Brettell \& Hollifield 2000), few have contextualised the individual personal and professional life experiences of the migrant and their family. This paper seeks to fill this gap. We focus on the professional, personal and socio-cultural issues experienced by Jordanian migrant nurses.

\section{Background and literature review}

The global migration of nurses has continued in an effort to alleviate the worldwide nursing shortage (International Council of Nurses 2007). Therefore, the poorer countries of Asia and sub-Saharan Africa are feeling the effects of this one-way emigration of trained health workers (Buchan J 2006). Nurses also migrate for personal reasons such as improving their economic status.

The United Kingdom (UK) is a major destination for healthcare workers from developing countries, with 49,780 foreign-born doctors $(33.1 \%$ of medical work force) and 50,564 foreign-born nurses comprising $8 \%$ of the total nursing work force, however this has dropped significantly since the mid of the last decade (Buchan \& Seccombe 2013). Jordan is one such country from which many nurses relocate to the UK to work. Much research has been conducted on top- ics such as the current international nursing shortage and the recruitment of nurses from various countries. International nurses have unique needs when adapting to new host cultures and workplaces (Xu 2006), but the literature has revealed little evidence of nurses' professional and personal experiences related to migration. According to Walters (2008), the actual experiences and stories of nurses qualified in other countries, particularly those from developing countries who migrated to developed countries, are neither well documented nor well examined.

Migration studies frequently neglect personal and professional transformations (Heaton et al. 1982, Choucri \& Brecke 1983, Findlay et al. 1998, Englander 2009, McGillis Hall et al. 2009, Yeates 2009, Singh \& Sochan 2010). The literature widely identifies the adaptation of immigrant nurses to major areas of need and the challenges that include communication, differences in nursing practices, regulation, unequal treatment and cultural dissimilarities (Chege 2010). These challenges affect not only the adaptation experiences of international nurses but also their intent to stay in the host country and the quality of patient care.

Jordan emerged as a country in the market of sending nurses to the UK in 1999 and to other Gulf Countries since the early 1980s (Jordanian Nursing Council 2005, Nursing \& Midwifery Council 2006). Therefore, it is important for both home and host countries (along with countries that share the same culture) to explore and examine the personal and professional experiences of Jordanian nurses who migrate. This study documents their experiences, illuminates their journeys and discusses implications for individuals, employers and policy makers.

\section{Methodology}

After approval from the Medical School Ethics Committee at the University of Nottingham, participants were recruited through the Nursing and Midwifery Council (NMC) and via snowball sampling. Both methods generated 52 willing study volunteers. However, participation in the interviews was restricted to respondents who met the criteria of maximum demographic variation (Sandelowski, 1995). The purpose of maximum variation was to ensure a group of participants who were different based on age, sex, geographical location of work, length of registration in the 
UK, migration pattern and marital status (see Table 1) to obtain a wide range of views.

In this qualitative study, semi-structured interviews were used to collect data. Questions included: 'How would you evaluate your experience in the UK?', 'Did you find difficulties?', and 'What are the differences in work between Jordan and the UK?' Thirteen face-to-face interviews were conducted by one of the researchers and 12 occurred by telephone due to difficulty with scheduling. Interviews were conducted in English over a six-month period and lasted approximately one hour, were audio recorded and transcribed verbatim. The transcripts were checked against the audiotape for accuracy and completeness.

Content analysis was used to analyse the text (Burnard 1991). To examine the meaning of the participants' experiences, the data were systematically analysed to identify categories through words and phrases (Hsich \& Shannon 2005). Coding schemas were derived from the data using the theme of the participants' migration experiences as a guide. We were interested in the interaction between nurses and their new environment on a professional and socialrelational level. The process was dynamic and repeated several times to ensure congruency of the categories. Data coding was facilitated using Nvivo 8 (NVivo qualitative data analysis software; QSR International Pty Ltd. Version 8, 2008 Victoria, Australia). The categories that were identified are described below.

\section{Results}

Demographic findings (see Table 1) indicated that more men than women participated in the study, reflecting the gender differences among nurses in Jordan and the nurses that tend to migrate (Ahmad \& Alasad 2007).

The overarching theme that guided the analysis was the transformational experiences of migrant nurses. Categories that emerged related to this theme were professional transformation, personal transformation and socio-cultural experiences.

\section{Professional transformations}

We define 'professional transformation' as the means of fulfilling one's nursing potential by directing oneself towards

Table 1 Participant profiles*

\begin{tabular}{|c|c|c|c|c|c|c|c|c|c|c|}
\hline \multirow[b]{2}{*}{ Interviewee name } & \multicolumn{3}{|l|}{ Age } & \multicolumn{2}{|c|}{ Gender } & \multicolumn{3}{|c|}{ UK registration } & \multicolumn{2}{|c|}{ Migration pattern } \\
\hline & $<30$ & $31-40$ & $>40$ & $\mathrm{M}$ & $\mathrm{F}$ & $<2$ years & $2-5$ years & $>6$ years & From Jordan & Via another country \\
\hline Sami & $\sqrt{ }$ & & & $\sqrt{ }$ & & $\sqrt{ }$ & & & & $\sqrt{ }$ \\
\hline Ayman & $\sqrt{ }$ & & & $\sqrt{ }$ & & & $\sqrt{ }$ & & $\sqrt{ }$ & \\
\hline Raed & $\sqrt{ }$ & & & $\sqrt{ }$ & & & $\sqrt{ }$ & & & $r$ \\
\hline Khaleel & $\sqrt{ }$ & & & $\sqrt{ }$ & & & & $\sqrt{ }$ & $\sqrt{ }$ & \\
\hline Malek & $\sqrt{ }$ & & & $\sqrt{ }$ & & $\sqrt{ }$ & & & & $\sqrt{ }$ \\
\hline Jawad & $\sqrt{ }$ & & & $\sqrt{ }$ & & & & $\sqrt{ }$ & $\sqrt{ }$ & \\
\hline Radhi & & $\sqrt{ }$ & & $\sqrt{ }$ & & & & $\sqrt{ }$ & & $\sqrt{ }$ \\
\hline Abdullah & & $\sqrt{ }$ & & $\sqrt{ }$ & & & $\sqrt{ }$ & & $\sqrt{ }$ & \\
\hline Salem & $\sqrt{ }$ & & & $\sqrt{ }$ & & & $\sqrt{ }$ & & $\sqrt{ }$ & \\
\hline Ibrahim & & $\sqrt{ }$ & & $\sqrt{ }$ & & & & $\sqrt{ }$ & $\sqrt{ }$ & \\
\hline Tayseer & & $\sqrt{ }$ & & $\sqrt{ }$ & & & $\sqrt{ }$ & & $\sqrt{ }$ & \\
\hline Maram & $\sqrt{ }$ & & & & $\sqrt{ }$ & & $\sqrt{ }$ & & $\sqrt{ }$ & \\
\hline Adel & $\sqrt{ }$ & & & $\sqrt{ }$ & & & & $\sqrt{ }$ & $\sqrt{ }$ & \\
\hline Wesam & & $\sqrt{ }$ & & $\sqrt{ }$ & & & & $\sqrt{ }$ & $\sqrt{ }$ & \\
\hline Adeeb & & $\sqrt{ }$ & & $\sqrt{ }$ & & & $\sqrt{ }$ & & & $\sqrt{ }$ \\
\hline Wejdan & & & $\sqrt{ }$ & & $\sqrt{ }$ & & & & $\sqrt{ }$ & \\
\hline Hassan & & $\sqrt{ }$ & & & & & & $\sqrt{ }$ & $\sqrt{ }$ & \\
\hline Yahya & & $\sqrt{ }$ & & $\sqrt{ }$ & & & & $\sqrt{ }$ & $\sqrt{ }$ & \\
\hline Saleh & & $\sqrt{ }$ & & $\sqrt{ }$ & & & & $\sqrt{ }$ & $r$ & \\
\hline Laila & $\sqrt{ }$ & & & & $\sqrt{ }$ & $\sqrt{ }$ & & & $\sqrt{ }$ & \\
\hline Talal & $\sqrt{ }$ & & & $\sqrt{ }$ & & $\sqrt{ }$ & & & $\sqrt{ }$ & \\
\hline Amal & & $\sqrt{ }$ & & & $\sqrt{ }$ & $\sqrt{ }$ & & & & $\sqrt{ }$ \\
\hline Muhannad & & $\sqrt{ }$ & & $\sqrt{ }$ & & & & $\sqrt{ }$ & & $r$ \\
\hline Muna & & $\sqrt{ }$ & & & $\sqrt{ }$ & & & $\sqrt{ }$ & $\sqrt{ }$ & \\
\hline Ziad & & $\sqrt{ }$ & & $\sqrt{ }$ & & & $\sqrt{ }$ & & $\sqrt{ }$ & \\
\hline
\end{tabular}

*All names are pseudo names, and all attributes of the participants were on the time of the interviews. 
adding more value to nursing. Two subthemes emerged related to professional transformation: work patterns and organisational patterns.

\section{Work patterns}

UK work patterns are guided by work policies and regulations, nursing schedules, protocols and guidelines. Because of this structure, each nurse's duties and responsibilities are well defined, and performance can be measured and appraised. As a result, nurses must complete multiple forms and paperwork to fulfil their duty:

Here [in the UK], they have more guidelines, more forms to fill out, more protocols and many things. But as a nurse, you do mainly the same things. [...] Everything has to be according to the standards, protocols and guidelines. In Jordan, we have few of these. (Amal)

Migration provided the opportunity for some nurses to recognise unprofessional and possible irresponsible behaviours on their part that were overlooked in Jordan, even though they were not acceptable behaviours. For example, part of the discipline policy in the UK prohibits loitering in the hospital. Some nurses lingered aimlessly in the hospital units in Jordan. One participant had a habit of wandering around during duty:

If you work in certain wards, you can go to visit other wards, which I used to do. Now... when I think about it, [...] it wasn't [a] good idea for me. I completely changed my mind. (Yahya)

Flexibility and part-time work opportunities in the UK provided Jordanian nurses with the opportunity to work in different places and to earn additional money while they do their original full-time job. The bank and agency nursing systems are not used in Jordan because all of these jobs are full-time, and no opportunity exists for part-time nursing. Overtime is used on a limited basis in Jordan; however, nursing managers rely on it heavily in the UK to overcome transient nursing shortages:

I do some shifts with them in the same hospital because there is lots of work available in the hospital. I don't need to travel to get [work] anywhere else. (Khaleel)

Nursing schedule patterns in the UK provide nurses with a sense of flexibility in performing their duties. Nurses in Jordan follow a rigid schedule, regardless of their productivity. For example, the only option available is full-time work with a two- or three-shift schedule, regardless of the nurse's circumstances. As a result, some nurses take the opportunity to find any loophole in the regulations to overcome this rigidity:
I did have problems [...] because my staff [...] used to come late or leave early or leave the patients sometimes. (Yahya)

In Jordan, the nurses would perform tasks such as drawing blood and applying intravenous (IV) canulas. However, these procedures were not part of the job description for most nurses in the UK, where physicians and specialists such as phlebotomists perform such tasks in critical care units. Jordanian migrant nurses were especially unhappy that some of their skills were not being recognised:

[In Jordan] I used to cannulate patients, take peripheral blood and did some clinical procedures that we are not allowed to do here. (Ayman)

Most Jordanian nurses had a great deal of experience. Not being allowed to perform tasks for which they were trained led to job dissatisfaction.

\section{Organisational patterns}

Three key elements that participants reported distinguish nursing care organisational patterns in the UK vs. Jordan. The first element is the influence of nursing manager turnover in the UK:

The idea of looking after people in the UK is more [related] to accountability. It's promoted by updated ideas and different people's input. [That is], renewing policies, new managers come in and old managers go out, which influences the work. (Abdullah)

A second element is applying a holistic nursing approach and evidence-based practice to nursing care. Nurses who migrated were exposed to the idea of practising holistic care:

Medicine here [is] more comprehensive. It covers social issues [and] emotional issues, how the patients are living and their conditions at home. We look at everything. [...] In Jordan, there was a concentration on curing [treating] people. You know, there were no social issues and no communication [with the patients]. A prescription was given to the patients, and that's it. (Abdullah)

Migrant nurses experienced a professional transformation as a result of the differences in the education and work policies in the UK, including the emphasis on evidence-based practice. One participant's account indicates that nursing in Jordan tends not to be as evidence-based:

$[E]$ verything is evidence-based practice here. So everything you read in the literature or in a book, you see it in the clinical setting. [...] In Jordan, I think there is a gap between research and the clinical setting. (Laila)

Another important aspect is the organisational structure of healthcare. According to the participants, patient care is 
provided by teams in the UK, whereas it is structured on a hierarchical basis in Jordan and the Gulf States:

[Here], we are team. In Jordan, there is no team. (Wesam)

Another participant, a team leader, also supported this finding. He stated that doctors in the UK are team members rather than leaders:

Basically, in the wards each night there is only one doctor, so they want somebody to manage the team there. The whole team is $18 \mathrm{G}$ grade and $6 \mathrm{~F}$ grade [staff], and there is me: I grade. (Muhannad)

Finally, it is not only the organisational differences between the source and destination country that influenced nurses' professional experience but also the personal and socio-cultural experiences. The next sections describe the kinds of personal and social challenges and transformations migrant nurses' encounter during their daily life to survive in the UK.

\section{Personal transformations}

A personal transformation is used here to identify a shift in thought or action to fulfil a person's potential by directing the self towards making a difference in their own work and life. Jordanian nurses were happy to talk about the personal changes that they experienced. One participant noted how the experience of migration had an enormous influence on his life. He explained:

[L]iving in the UK is different from living in Jordan. I think I've got more experience and chances here than in Jordan. [...] A firstworld country gives you more ideas about life. (Abdullah)

His attitudes shifted due to the formation of new life perspectives as a result of living in a different country. When asked about his new life, he said:

I've become calmer, and I take more time to make a decision. It influenced my way of thinking and my way of understanding life. (Abdullah)

Women also gained new attitudes that transformed their sense of self and status. One woman remarked about her life in the UK:

I think this has boosted my confidence, autonomy, independence, and [ability to live] on my own. (Amal)

This statement implies that these nurses have reflected on their original identities and gained additional perspectives that broadened their experiences (Caldas-Coulthard \& Iedema 2008). In Jordan, they lived in a single cultural community where things are taken for granted and without question. Moving to a different culture raises new insights about behaviours such as eating food:

$[\mathrm{W}]$ hen we arrived, the last thing we thought of was the food. Then, we faced the fact that we are Muslims, and we must eat halal food and stuff like that. (Abdullah)

Contrary to the expectation that the migrants' values would be changed by the influence of the host society, the Jordanian nurses' values and identity seem to have become confirmed:

We have been here five years. We've had a lot of challenges to face. But I have to say that we discovered [that] it strengthened our beliefs more than making them weak or get away from our culture and our religion. (Maram)

Life on a daily basis for single women in Jordan is easier than some might think. Yet, the more liberal lifestyle in the UK provided women with the opportunity to lead a life without the restrictions of their home culture:

I felt more free during the day to go and shop. [...] I didn't really find it difficult to wear a hijab here... it's a very open country here, and they respect other people's faiths, practices and religions.... So what I'm wearing back home I'm wearing here, and I haven't had any problem. (Amal)

When we asked a married female nurse about her advice for Jordanian women willing to live and practise nursing in the UK, she noted:

It comes down to their personality and their attitude and how they think, and if they have a strong belief, [then] nothing can change it. [...] If they have any doubt, that's going to be a breaking point for them, and they will not be able to carry on. (Maram)

Next, we report and examine how the Jordanian nurses experienced the transformation in a cultural context.

\section{Socio-cultural transformations}

The factor that determined the ultimate transformation associated with the nurse migration experience was the social status of the migrant in their home and host countries:

In the UK, I see every single culture in the world. I heard about countries that I have never heard about, and I met people who I never expected to meet in my life, from all sorts of cultures and all sorts of backgrounds.... (Abdullah).

Professional transformations were not the only feature of nurse's experience; socio-cultural transformations were important and linked with personal transformations. 
Cultural encounters involved exposure to different values and beliefs. Nurses in Jordan were familiar with patients who came from their cultural milieu. They had no need to know about other cultures to provide nursing care:

Jordan is not a multicultural society, not at all; it's just one kind of people and one culture. [...] I did [treat] Arab people from different countries like Yemen and maybe Libya. But I couldn't call it a multicultural environment. (Abdullah)

The nurses wanted to learn about other cultures, opportunities that would not have come without leaving Jordan:

I didn't have the chance to be exposed to this multicultural [environment]. (Ibrahim)

The cultural competency of the nurses developed as they continuously learnt via their exposure to different cultures. Jordanian female nurses had interesting views about working in a multicultural setting:

You have to understand the way they think, their religious practices [...]. So being open may be what makes people approach you, understand you and be ready to deal with you. (Amal)

The core of Jordanian nurses' social life is their family, particularly their nuclear family then with their parents' families in Jordan and their Jordanian friends in the UK. We asked the participants who they would tell first if an important event occurred. One nurse answered:

[...] my wife because she lived [through my difficult times]. I should share [with] her the happiness. (Ibrahim)

He added:

[...] [m]y family back home. I always update them with good things and bad things. (Ibrahim)

Most Jordanian nurses in the UK interacted with each other socially:

I have good connections here with Jordanians, which is the same culture [as my own]. (Ibrahim)

Because most of the nurses came to the UK on their own, they developed positive interpersonal relationships. When single, they would first share all of their good and bad news with a friend. When we asked one single male participant with whom he would first share his good or bad news, he said:

[...] [m]y friend [...]. So, if I need something, my friend will come and talk to me and tell me what to do. (Malek)

Some nurses noted that socialising with their British counterparts might involve attending pubs, public and pri- vate parties. They were anxious about attending events where alcohol was usually served because Muslims are forbidden from consuming alcohol:

[W] hen you go for a night out with your group, once you tell them [that], for example, I don't drink alcohol, they respect your ways. Nobody will push you or encourage you to drink even one sip of alcohol. (Tayseer)

Food and drink play an important part in connecting people because both are involved in most social gatherings. However, some participants noted the constraints for Jordanian nurses seeking to socialise with their British counterparts. Although Jordanian nurses are tolerant and accept other people's freedom of choice, they understand their own freedom to choose not to drink alcohol:

It is a cultural and religious [edict]. Because I don't drink, I don't party. So if you want to be involved with English colleagues they always go for parties [and] drink, and that doesn't suit me. So I try to be with friends who know what my culture is. (Khaleel)

Socialising with Jordanian friends enabled them to share interests:

[We are] always talking about work; we also discuss about family life, troubles, happiness, good things and bad things. (Ibrahim)

However, socialising with people of the same nationality was not always a positive choice for new migrants. Many adverse effects emerged from this choice, particularly the delay in learning to speak the language of the host country:

[B]eing in a group was delaying our progress; we sat together and spoke in Arabic, and the language was quite a challenge for us. [...] That delayed our progress and our ability to speak the English language. (Abdullah)

Discrepancies in values did not stop Jordanian nurses from socialising when there were other means of connection. Participants reported that feelings of loneliness and the presence of children often promoted new relationships, at least with one's neighbours:

We lived in a third floor flat. [On] the first floor [lived] a Jewish lady, and [on] the second floor [lived] a Christian. We lived together for 4 years; [it was] peaceful and nice. [...] We supported each other. [...] My wife was not feeling really secure and happy before that, particularly when I had to do some night shifts from time to time. (Wesam)

This participant admitted that his wife felt lonely in a foreign country, and she had formed false assumptions about what others from different cultures were doing before establishing these relationships. 
Building social networks with one's neighbours within UK society is not a one-day activity. It took an extended period because both the foreigners and the natives must earn each other's trust:

Slowly, she was a bit, you know, open to the community. She visited our neighbours just to say hello. She has a relationship with two or three of our neighbours. (Wesam)

Some family members in Jordan received constant or intermittent financial support from their sons or daughters who worked in the UK. Jordanian nurses, living as diaspora, were economic and social assets to their parents, brothers and sisters back home:

[W] 've got many responsibilities back home. We have to help our family. I do some extra work to send [money] to my parents. [...] It's our culture [to do so]. (Ayman)

While some participants arrived in the UK alone, most were married and brought their families after arrival. Once their families arrived, they led a different life from the one they had experienced as singles. It was expensive to live in the UK for a family from Jordan. This expense challenged families to survive on one person's income, particularly when children were present. Most nurses with families were already the primary breadwinners:

I am supporting my family here, and I'm the only employed. My wife doesn't work over here. So that makes the situation a bit [...] harder for me. (Jawad)

Jordanian families in the UK were faced with financial problems, and some parents dealt with this situation by working part-time and alternating shifts. Some families successfully used this approach. Two male participants were married to working nurses, and their wives worked. However, both families were planning to save money to provide their wives the opportunity to stay at home. The underlying reason was to care for the children:

[I]t's difficult to look after our kids who are 8 and 9 years old and need somebody to teach them, talk to them, [and] play with them. (Muhannad)

Children were an opportunity for migrant nurses' families to socialise and integrate with their local communities:

[My wife] was taking one of our kids to nursery for 2 and a half years. She was volunteering for some activities at the school as well. They let her give a ten-minute speech to the kids and families to explain what Eid al-Fitr means to the Muslims. (Wesam)

According to two married participants, their volunteer work in the community gave them access to other activities in the community. One wife talked about integrating with the rest of UK society. She had been unemployed for three years after her arrival from Jordan. She noted:

[C]ooking, cleaning, looking after the children, shopping, discovering the area around me and talking to the neighbours; this period gave me a good idea about the country, [its] rules and what to do in case of an emergency. That made me a stronger woman. (Wejdan)

This account indicates the importance of holidays and off-duty time for socialising. With their time and energy consumed by their day or night duties, nurses were not able to participate in many social activities. Dual-nurse families had no time to socialise off duty because:

[S]omebody needs to stay at home with the kids; so my husband and I alternated our shifts at work. (Wejdan)

Without alternating their shifts, nurses with nursespouses had trouble minding their children. When they were in Jordan, their parents assumed the role of bringing up the children, so they had no need for childcare services. This was a major adjustment.

\section{Discussion}

The experiences of migrant nurses are embedded in their profession, families, workplaces and local communities in the host country and in their families, relatives and friends in their home country. Moreover, their experiences were influenced and embedded within larger national and international economic, political and cultural institutions (Maton 2000). Migrant nurses as individuals might be judged as people who learn and develop; however, their actions may not be affected by new surrounding social structures (Engeström 1999).

Migrant nurses' experiences portray differences in the work setting between the UK and Jordan. These differences influence their professional and personal lives, regardless of the transferability of their professional skills that are used as a passport to reach their host countries (Choy 2003, Ineson \& Seeling 2005, Percot 2005). Although their nursing skills have considerable transferability, their sense of professionalism and the actual work policies and the regulations differ between countries (Winkelmann-Gleed 2006). From the perspective of migrant nurses, their nursing skills and previous experience from their home countries do not contribute as much as they had expected in their adaptation to their new workplace milieu. Jordanian nurses are confronted with new policies and working patterns, such as schedules and job descriptions. These changes became clear 
within a few months of their arrival. Many Jordanian nurses in the UK reflect on themselves and others by making cross-cultural comparisons and ascertaining what they have in common with and what makes them different from British nurses.

Jordanian nurses experienced imperfect work patterns prior to their arrival and welcomed the employment conditions in the UK. Importantly, although some aspects of their new work patterns represented positive changes, some of their nursing skills were no longer applicable. This is supported by some, although inconsistent literature with regard to 'de-skilling migrant nurses' (Matiti \& Taylor 2005, Bloch 2006, Smith et al. 2006).

People are immersed in their culture and take it for granted (Hofstede \& Hofstede 2005). Culture influences behaviour and thinking, and it is deeply ingrained in the sense of self. When people move to a foreign country, their cultural programming is thrown into disarray. Yet, many Jordanian nurses did not have contradicting identities because they moved to the UK. The experience of living in the UK allowed these nurses to reflect on their own culture and how their new experiences impacted their values, beliefs and behaviours. Most nurses learnt much from their migration experiences, and added new ideas to their original cultural beliefs. As these nurses adopted more diverse perspectives, they became more confident of their Jordanian heritage and their nursing identities, despite professional and personal transformational experiences. The maintenance of their Jordanian identity was influenced by their continuous contacts and visits to Jordan. Moreover, their parents and close relatives in Jordan continued to be a big part of their lives, even while living abroad. (Antoun 2005).

When some nurses come to a host country, they have expectations of what to expect based on their home country. In the host country, they face demands from their new professional and personal lives. Nevertheless, some nurses discovered that they do not achieve their expectations of professional and interpersonal experiences and, after a while, they modify their expectations, migrate to another country or return home.

\section{Limitations}

This study focused on individuals and did not try to evaluate the pros and cons or motivations of nursing migration from source to the host country. Rather, this research focused on the professional and personal migration experiences of Jordanian nurses working in the UK. Although only 25 nurses were interviewed, the results represented input from a broad range of demographics.

\section{Conclusions}

This paper explored the experience of living and working in another country. It identified the professional and life transformations that are major features of migrant nurses' experiences during the post-transition phase. They were influenced by their experiences in the new country; however, they also retained their basic beliefs and values.

Professional transformation is the outcome of integrating into a new work place, and it is promoted by differences in the policies, regulations and values associated with nursing practices between the source and host countries. This shift provides the migrants with a standard of work and the ability to work worldwide. These nurses are likely in a better position to choose among workplaces in the future and will have some insight about adaptation to a new professional and personal culture.

\section{Relevance to clinical nursing practice}

To provide high-quality nursing care, it is critical to understand the transformation experience to expand our sense of self as a person and as a nurse, gaining a degree of control over how we can practise when we move anywhere in the world. If we are able to work, then we can make a difference. Making a difference can be challenging, especially for migrant nurses who live in the unique situation of working within a foreign dominant culture, building quality relationships, providing care under different professional structures and expectations.

\section{Acknowledgements}

We are grateful to all the Jordanian nurses who participated in this study and to the University of Nottingham - UK which supported this study through the SNMP Alumni Award.

\section{Disclosure}

The authors have confirmed that all authors meet the ICMJE criteria for authorship credit (www.icmje.org/ethical_1author.html), as follows: (1) substantial contributions to conception and design of, or acquisition of data or analysis and interpretation of data, (2) drafting the article or revising it critically for important intellectual content and (3) final approval of the version to be published.

\section{Conflict of interest}

No conflict of interest. 


\section{References}

Ahmad MM \& Alasad JA (2007) Patients' preferences for nurses' gender in Jordan. International Journal of Nursing Practice 13, 237-242.

Antoun RT (2005) Documenting Transnational Migration: Jordanian Men Working and Studying in Europe, Asia, and North America. Berghahn Books, New York, NY.

Arango J (2000) Explaining migration: a critical view. International Social Science Journal 52, 283-296.

Bloch A (2006) Emigration from Zimbabwe: migrant perspectives. Social Policy and Administration 40, 67-87.

Brettell CB \& Hollifield JF, eds (2000) Migration Theory: Talking Across Disciplines. Routledge, London, pp. $1-26$.

Buchan J (2006) Evidence of nursing shortages or a shortage of evidence? Journal of Advanced Nursing 56, 457-458.

Buchan J \& Seccombe I (2013) The end of growth? Analysing NHS nurse staffing. Journal of Advanced Nursing 69, 2123-2130.

Burnard P (1991) A method of analysing interview transcripts in qualitative research. Nurse Education Today 11, 461-466.

Caldas-Coulthard CR \& Iedema R (2008) Identity Trouble: Critical Discourse and Contested Identities. Palgrave Macmillan, Basingstoke, p. 295.

Chege N (2010) Adaptation challenges facing internationally educated nurses. Dimensions of Critical Care Nursing 29, 131-135.

Choucri N \& Brecke P (1983) Migration in the Middle-East - transformation and change. Middle East Review 16, 16-27.

Choy CC (2003) Empire of Care: Nursing and Migration in Filipino American History. Duke University Press, Durham, NC.

Engeström Y (1999) Activity theory and individual and social transformation. In: Perspectives on Activity Theory (Engeström Y, Miettinen R \& Punamäki R-L, eds.). Cambridge University Press, Cambridge, UK. pp. 19-38.

Englander K (2009) Transformation of the identities of nonnative English-speaking scientists as a consequence of the social construction of revision. Journal of Language, Identity and Education 8, 35-53.

Findlay AM, Jones H \& Davidson GM (1998) Migration transition or migration transformation in the Asian dragon economies? International Journal of Urban and Regional Research 22, 643-664.

Fussell E \& Massey DS (2004) The limits to cumulative causation: international migration from Mexican urban areas. Demography 41, 151-171.

Heaton TB, Hawley AH, Udry JR, Leoprapai B \& Cardona R (1982) Migration and the transformation of employment and household structures. Singapore Journal of Tropical Geography 3, 34-43.

Hofstede G \& Hofstede GJ (2005) Cultures and Organizations, Software of the Mind. McGraw-Hill, London.

Hsich HT \& Shannon S (2005) Three approaches to qualitative analysis. Qualitative Health Research 15, 1277.

Ineson S \& Seeling SS (2005) The medical passport. Journal of Continuing Education in the Health Professions 25, 30-33.

International Council of Nurses (ICN) (2007) Press Release: The Time for a UN Agency for Women is Now Says the International Council of Nurses. ICN, Geneva.

Irene AG, Rita B \& Hans M (2010) Purchasing health services abroad: practices of cross-border contracting and patient mobility in six European countries. Health Policy (Amsterdam, Netherlands) 95, 103-112.

Jordanian Nursing Council (2005) Situation Analysis of Nursing in Jordan. Jordanian Nursing Council, Amman.

Matiti M \& Taylor D (2005) The cultural lived experience of internationally recruited nurses: a phenomenological study. Diversity in Health and Social Care 2, 7-16.

Maton KI (2000) Making a difference: the social ecology of social transformation. American Journal of Community Psychology 28, 25-57.

McGillis Hall L, Pink GH, Jones CB, Leatt P, Gates M \& Peterson J (2009) Is the grass any greener? Canada to United States of America nurse migration. International Nursing Review 56, 198-205.
Nursing and Midwifery Council (2006) Statistical Analysis of the Register. Nursing and Midwifery Council, London.

Okougha M \& Tilki M (2010) Experience of overseas nurses: the potential for misunderstanding. British Journal of Nursing (Mark Allen Publishing) 19, 102-106.

Percot M (2005) Indian nurses in the Gulf: two generations of female migration. In Sixth Mediterranean Social and Political Research Meeting. European University Institute, Robert Schuman Centre for Advanced Studies, Montecatini Terme, France.

Sandelowski M (1995) Sample size in qualitative research. Research in Nursing of Health 18, 179-183.

Singh MD \& Sochan A (2010) Voices of internationally educated nurses: policy recommendations for credentialing. International Nursing Review 57, 56-63.

Smith P, Allan H, Henry L, Larsen JA \& Mackintosh M (2006) Valuing and recognising the talents of a diverse workforce from the REOH study. In: The REOH study. University of Surrey, England.

Walters H (2008) The experiences, challenges and rewards of nurses from South Asia in the process of entering the Australian nursing system. Australian Journal of Advanced Nursing 25, 95-105.

Winkelmann-Gleed A (2006) Migrant Nurses: Motivations, Integration and Contribution. Radcliffe Publishing, Oxford.

World Health Organisation (WHO) (2006) The World Health Report 2006 Working Together for Health. WHO, Geneva. Available at: http:// www.who.int/whr/2006/en/ (accessed 22 February 2013).

$\mathrm{Xu} \mathrm{Y} \mathrm{(2008)} \mathrm{Facilitating} \mathrm{adaptation} \mathrm{of}$ international nurses: Need for an evidence-based transition and integration program. Home Health Care Management \& Practice 20, 199-202.

Yeates N (2009) Production for export: the role of the state in the development and operation of global care chains. Population Space and Place 15, 175-187. 